\title{
Characteristics of Self-Compacting Concrete with Different Size of Coarse Aggregates and Alccofine
}

\author{
Prithiviraj Chidambaram* and Saravanan Jagadeesan
}

Department of Civil and Structural Engineering, Annamalai University, Chidambaram 608002, India

('Corresponding author's e-mail: rajprithivi3@gmail.com)

Received: 27 March 2021, Revised: 11 June 2021, Accepted: 27 June 2021

\begin{abstract}
The findings of an experiment examining the efficacy of different size of coarse aggregates on the fresh and strength properties of Self-Compacting Concrete (SCC) and Alccofine based SCC are described in this article. For this study, 5 different coarse aggregate sizes $(10-4.75,12.5$ - 10, 16 - 12.5, 20 - 16 and $20-4.75 \mathrm{~mm}$ ) were used with conventional SCC to determine the workability and strength properties. The water to binder ratio of 0.4 is maintained for all mixtures. Workability properties like slump-flow, T50 time, V-funnel and L-box tests and hardened property of compressive strength were studied. From the conventional SCC results based on sufficient fresh and strength values, the optimal blend is chosen and analyzed further with Alccofine substitution of 10, 20, 30, 40, 50 and $60 \%$. The test results revealed that the maximum size of aggregate did not influence much on the workability. Whereas the combination of aggregate sizes with the replacement of cement by $30 \%$ of Alccofine had given optimum results on fresh and strength properties. Also, a numerical analysis was carried out, with Finite Element Modeling (FEM) to analysis the compressive strength and compared them to experimental findings. The consequence of FEM shows it is a reliable technique to validate experimental data.
\end{abstract}

Keywords: Self-compacting concrete (SCC), Coarse aggregates, Alccofine, Fresh properties, Compressive strength

\section{Introduction}

Normally concrete is defined as composite materials which bind the aggregate together with the cementitious material. These types of normal composites are facing some difficulties during placing at congested reinforcement, deep beams and some other complicated structures. The major difficulties are external vibration and the flowing of the matrix. To overcome these problems a special concrete called SCC is introduced in the recent era. SCC is a special concrete with differed mix proportions when compared to mechanically vibrated concrete. The size of the particles in SCC is essential for their flowability and homogeneity. Among all the ingredients of concrete coarse aggregates are occupying more volume. The improper size selection of it may affect the rheological properties. Instead of using single graded aggregates mixed size of aggregate can enhance the strength due to its packing density. Also, SCC is a trending technology for their self-compacting nature and improved strength even at complicated places of structures. It satisfies the strength characteristics which is the major concern of concrete and also provides a better and smooth finishing with homogeneous dense. However, the ingredients of SCC are similar to conventional concrete, but the percentage of finer particles should be more than the ordinary concrete. While selecting the ingredients of SCC special attention has to be given to satisfy the flow and strength properties. Generally, SCC influence several factors such as powder contents, water binder ratio, the dosage of chemical admixtures, mix proportions and size of aggregates etc. The fresh properties of SCC are prejudiced by the water binder ratio and SP dosage. The suitable range of these 2 parameters will enhance the workability of SCC. The paste content of concrete is influencing the workability whereas aggregate content bonded by paste after hardening is influencing the strength of SCC. The workability can be easily increased by increasing the water binder ratio but the addition of more water may cause the adverse effect of bleeding and segregation which may affect strength and durability. To overcome these effects the use of chemical admixtures like High Range Water Reducer (HRWR), Viscosity Modifying Agent (VMA) and Superplasticizer (SP) are introduced in SCC up to the allowable limits. 
Domone carried out the analysis of over 70 case studies and found that most of the researchers (around $70 \%$ ) were used coarse aggregates of size from 16 to $20 \mathrm{~mm}$ for their investigations [1]. It is also observed that the homogeneity of concrete may be affected by increasing the aggregate size [2]. Compared to all other ingredients they are available at a low cost hence care has to be taken by selecting the type of aggregate [3]. The high strength concrete can be achieved by the use of graded aggregates which improves the consistency of SCC and producing dense concrete. Also, the dense concrete can be achieved by different size fractions of coarse aggregate [4]. The use of $5-20 \mathrm{~mm}$ coarse aggregate had a compact single layer, thereby reducing the thickness of the mortar which could lower costs [5]. As per EFNARC guidelines, the suggested volume of coarse aggregate for SCC should not exceed $40-50 \%$ of the total volume of solid content and a maximum nominal size of $20 \mathrm{~mm}$ to preserve the better flow and to reduce segregation [6]. This limited aggregates volume directly increasing the powder content and thus increasing the cost of production which is the major drawback of SCC [7]. To obtain the cost-effective SCC the utilization of mineral admixtures and industrial by-products are encouraged i.e., the Supplementary Cementitious Materials (SCM) are performing a fundamental role in SCC. The usages of different types of mineral additives are necessary to minimize the amount of cement and to overcome the drawback of carbon-di-oxide emission produced by the cement [8,9]. The commonly used mineral admixtures are Rice Husk Ash, Fly Ash, Ground Granulated Blast Furnace Slag (GGBS), Metakaolin, Silica Fume and Alccofine etc.

Among these Alccofine is a new generation, micro-fine SCM with the finest particle size and specially regulated granulation. It is a glass-based SCM made from ultrafine slag content derived from steel or iron industries. Alccofine has astonishing effects to increase the overall performance of concrete in fresh and hardened states due to its higher specific surface area. Furthermore, adding Alccofine to the paste component improves the packing density, lowering water demand and admixture dosage thus improving the concrete's durability and strength parameters [10-14].

In this research work, the effect of different size of aggregates on the characteristics of conventional SCC has been studied initially. For that 5 different sizes of coarse aggregate, groups are taken such as 10 $4.75,12.5-10,16-12.5,20-16$ and $20-4.75 \mathrm{~mm}$ and the mixes are prepared. From the conventional SCC test results based on sufficient fresh and strength values, the optimal blend is chosen. For that 6 mixes are prepared and analyzed further with Alccofine substitution of 10, 20, 30, 40, 50 and $60 \%$. All the mixtures are prepared with a constant water binder ratio of 0.4 and an SP dosage of $1 \%$. The slump flow, $\mathrm{T}_{50}, \mathrm{~V}$-funnel, L-box and compressive strength tests are carried out.

\section{Experimental procedure}

The step by step procedure for the current study is illustrated as flow chart in the Figure 1.

\section{Materials and methods}

\section{Materials}

Ordinary Portland cement (OPC-53 grade) that confirming to IS 12269-1987 [15] and mineral admixture of Alccofine 1203 is used as cementitious materials. Alccofine 1203 is a specially processed slag based product with high glass content and superior reactivity which is purchased from Counto Micro fine products Pvt. Ltd. Goa. The chemical composition of cement and Alccofine are shown in Table 1. 


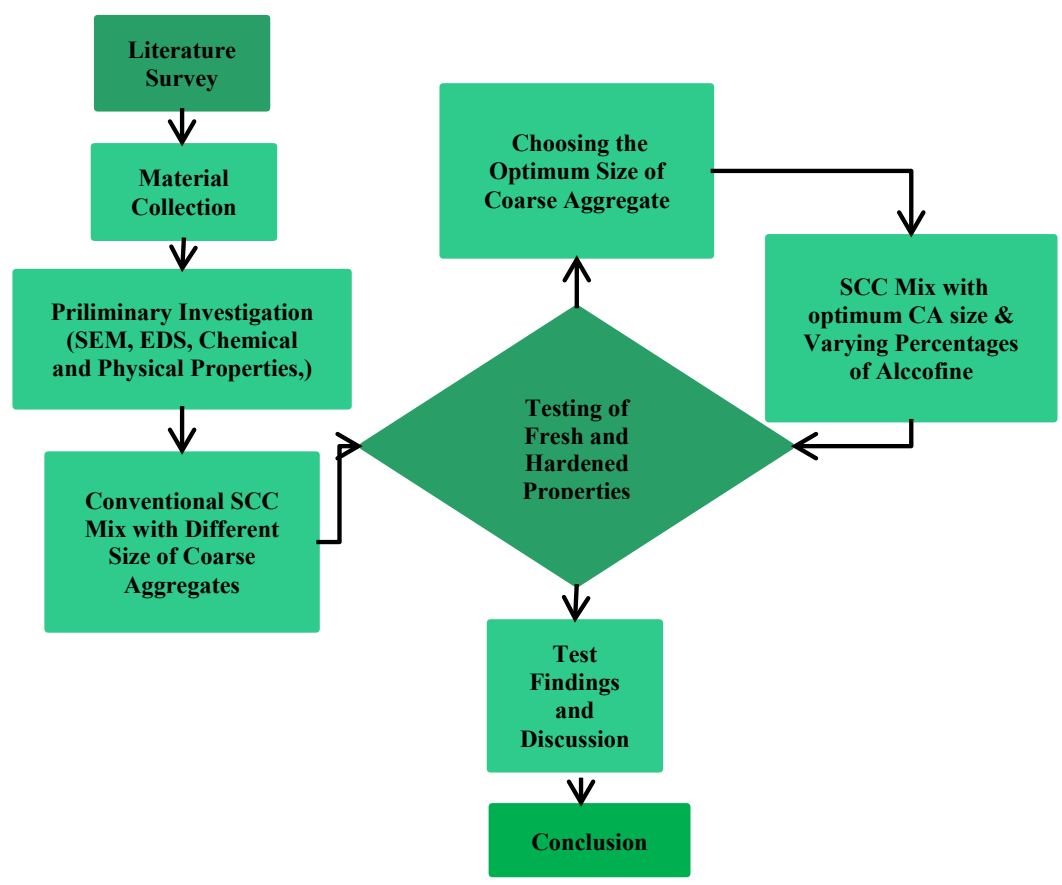

Figure 1 Flowchart of this investigation.

The Scanning Electron Microscope (SEM) at 5000× magnification of $5 \mu$ and Energy Dispersive XRay Spectroscopy (EDS) outputs of OPC 53 grade and Alccofine particles are shown in Figure 2. It is clear that cement particles are spherical, and Alccofine is irregular in shape with sharp edges. River sand is used as fine aggregate (Zone-III) and coarse aggregates were segregated by size. It was sieved and divided into 5 groups: Passing through $10 \mathrm{~mm}$-retained on $4.75 \mathrm{~mm}$, similarly 12.5 - 10, 16 - 12.5, 20 - 16 and $20-4.75 \mathrm{~mm}$ conforming to IS 383-1970 [16]. Figure 3 shows the grading curves of different types of aggregates. Superplasticizer (polycarboxylic ether) of BASF Master Glenium sky 8233 confirming to IS: 9103-1999 [17] is used. Ordinary tap water is used in the complete experimental work. The physical properties of constituent materials are listed in Table 2.
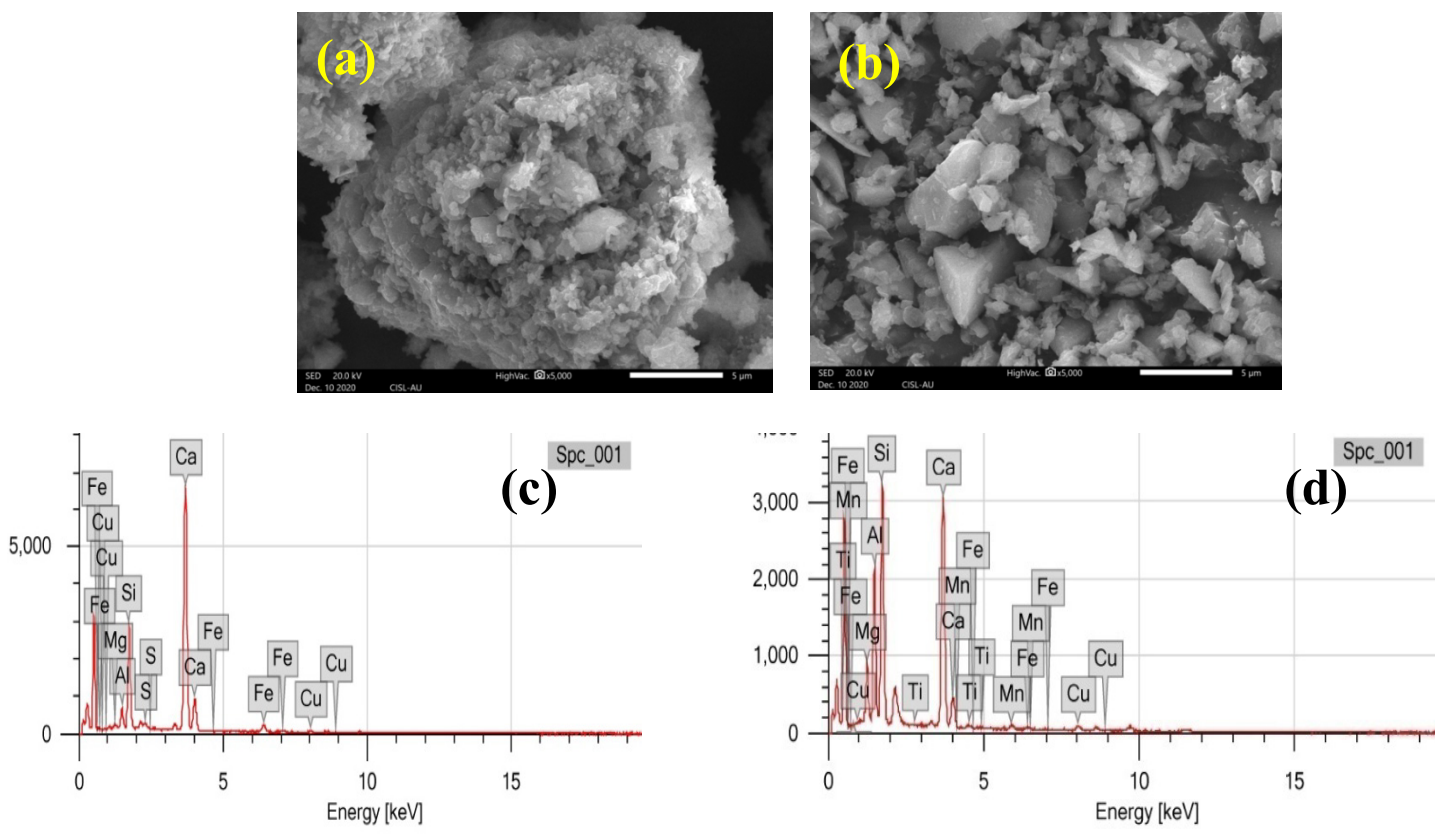

Figure 2 SEM (a) and (b) and EDS (c) and (d) outputs of OPC and Alccofine 1203. 
Table 1 Chemical composition of OPC and Alccofine 1203.

\begin{tabular}{ccc}
\hline & Chemical composition (\%) & \\
\hline Component & Cement & Alccofine 1203 \\
\hline $\mathrm{CaO}$ & 66.67 & 32.20 \\
$\mathrm{SiO}_{2}$ & 18.91 & 35.30 \\
$\mathrm{Fe}_{2} \mathrm{O}_{3}$ & 4.94 & 1.20 \\
$\mathrm{Al}_{2} \mathrm{O}_{3}$ & 4.51 & 21.40 \\
$\mathrm{SO}_{3}$ & 2.5 & 0.13 \\
$\mathrm{MgO}$ & 0.87 & 6.20 \\
$\mathrm{~K}_{2} \mathrm{O}$ & 0.43 & - \\
$\mathrm{Na}_{2} \mathrm{O}$ & 0.12 & - \\
Loss of ignition & 1.05 & - \\
\hline
\end{tabular}

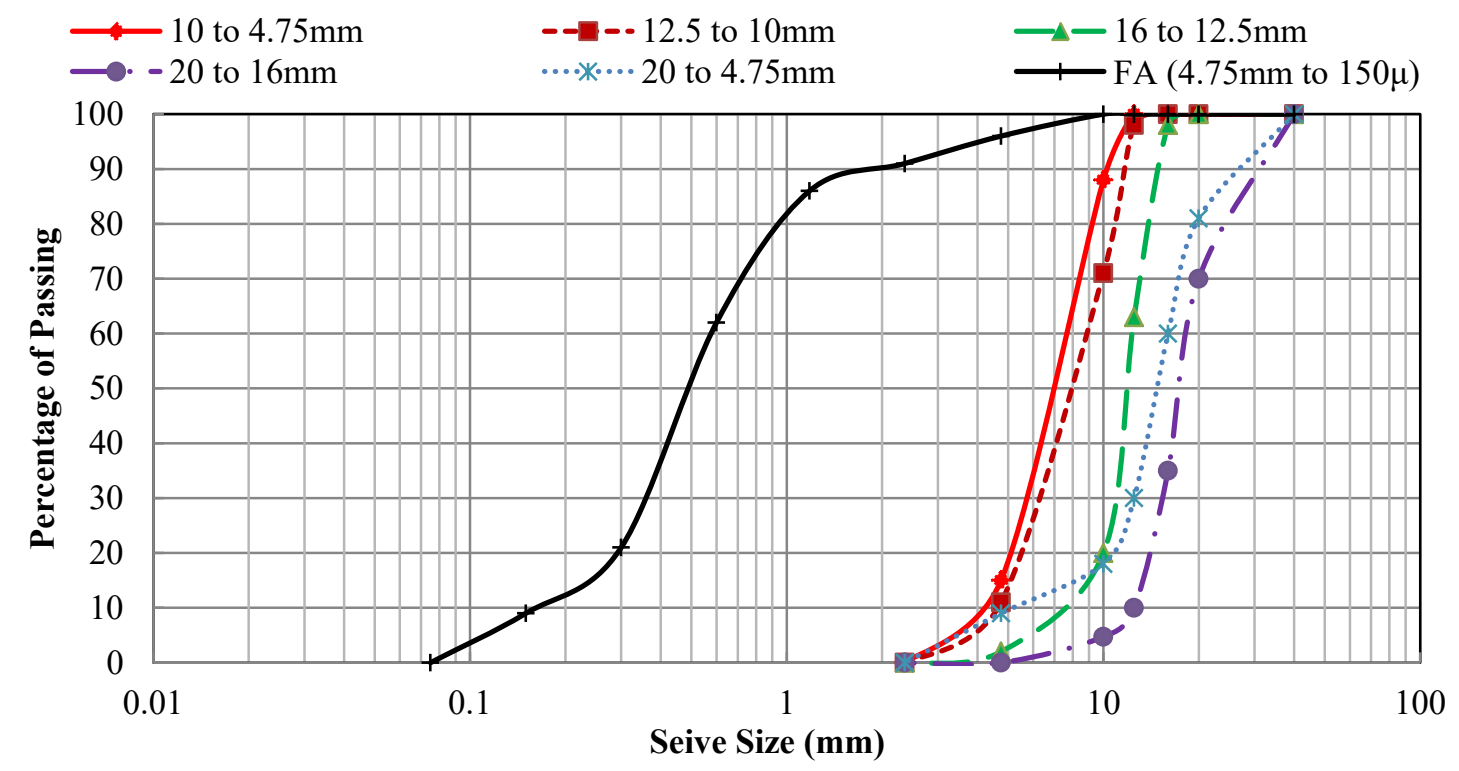

Figure 3 Sieve analysis of the different sized aggregates.

Table 2 Physical properties of constituent materials.

\begin{tabular}{cccccc}
\hline Description & Size & $\begin{array}{c}\text { Specific } \\
\text { gravity }\end{array}$ & $\begin{array}{c}\text { Water } \\
\text { absorption }\end{array}$ & $\begin{array}{c}\text { Fineness } \\
\text { modulus }\end{array}$ & $\begin{array}{c}\text { Specific surface } \\
\text { area }\end{array}$ \\
\hline Cement & $90 \mu$ & 3.15 & - & - & $225 \mathrm{~m}^{2} / \mathrm{kg}$ \\
Alccofine & 4 to $6 \mu$ & 2.86 & - & - & $1200 \mathrm{~m}^{2} / \mathrm{kg}$ \\
Fine Aggregate & $<4.75 \mathrm{~mm}$ & 2.68 & 0.42 & 2.88 & - \\
& 10 to $4.75 \mathrm{~mm}$ & 2.683 & 0.64 & 4.72 & - \\
Coarse Aggregate & 12.5 to $10 \mathrm{~mm}$ & 2.68 & 0.77 & 5.81 & - \\
& 16 to $12.5 \mathrm{~mm}$ & 2.7 & 0.83 & 6.97 & - \\
& 20 to $16 \mathrm{~mm}$ & 2.73 & 1.1 & 7.13 & - \\
& 20 to $4.75 \mathrm{~mm}$ & 2.7 & 0.92 & 7.08 & - \\
\hline
\end{tabular}




\section{Mixture proportions}

Five conventional SCC mixes for 5 different aggregate size groups are prepared and 6 Alccofine based SCC mixes for the optimum blend are prepared and examined in this investigation. The conventional SCC mixes are named $\mathrm{C} 1, \mathrm{C} 2, \mathrm{C} 3, \mathrm{C} 4$ and $\mathrm{C} 5$ which represents the range of aggregate sizes $10-4.75,12.5$ - 10, $16-12.5,20-16$ and $20-4.75 \mathrm{~mm}$, respectively. Alccofine mixes are named C5A10, C5-A20, C5-A30, C5-A40, C5-A50 and C5-A60. In this C5 represents the aggregate size of 20 $4.75 \mathrm{~mm}$ and $\mathrm{A} 10$ to $\mathrm{A} 60$ represents the percentage replacement of Alccofine. All the mixtures are prepared with a constant water binder ratio of 0.4 and an SP dosage of $1 \%$. Table 3 represents the mixture proportions of all the SCC mixes.

Table 3 Composition of SCC Mix proportions.

\begin{tabular}{cccccccc}
\hline Mix ID & $\begin{array}{c}\text { Cement } \\
\left(\mathbf{K g} / \mathbf{m}^{3}\right)\end{array}$ & $\begin{array}{c}\text { Alccofine } \\
\left(\mathbf{K g} / \mathbf{m}^{\mathbf{3}}\right)\end{array}$ & $\begin{array}{c}\mathbf{W a t e r} \\
\left(\mathbf{K g} / \mathbf{m}^{3}\right)\end{array}$ & $\begin{array}{c}\mathbf{W} / \mathbf{B} \\
\mathbf{r a t i o}\end{array}$ & $\begin{array}{c}\text { Coarse } \\
\mathbf{a g g r e g a t e} \\
\left(\mathbf{K g} / \mathbf{m}^{\mathbf{3}}\right)\end{array}$ & $\begin{array}{c}\text { Fine } \\
\mathbf{a g g r e g a t e} \\
\left(\mathbf{K g} / \mathbf{m}^{\mathbf{3}}\right)\end{array}$ & $\begin{array}{c}\mathbf{S P} \\
\left(\mathbf{K g} / \mathbf{m}^{\mathbf{3}}\right)\end{array}$ \\
\hline C1 & 465 & - & 186 & 0.4 & 831 & 915 & 4.65 \\
$\mathrm{C} 2$ & 465 & - & 186 & 0.4 & 830 & 915 & 4.65 \\
$\mathrm{C} 3$ & 465 & - & 186 & 0.4 & 836 & 915 & 4.65 \\
$\mathrm{C} 4$ & 465 & - & 186 & 0.4 & 845 & 915 & 4.65 \\
C5 & 465 & - & 186 & 0.4 & 836 & 915 & 4.65 \\
C5-A10 & 418.5 & 46.5 & 186 & 0.4 & 836 & 915 & 4.65 \\
C5-A20 & 372 & 93 & 186 & 0.4 & 836 & 915 & 4.65 \\
C5-A30 & 325.5 & 139.5 & 186 & 0.4 & 836 & 915 & 4.65 \\
C5-A40 & 279 & 186 & 186 & 0.4 & 836 & 915 & 4.65 \\
C5-A50 & 232.5 & 232.5 & 186 & 0.4 & 836 & 915 & 4.65 \\
C5-A60 & 186 & 279 & 186 & 0.4 & 836 & 915 & 4.65 \\
\hline
\end{tabular}

\section{Sample preparation and mixing practice}

The mixtures are prepared based on the guidelines provided by the EFNARC. The required quantities of materials for each mix are arrived and batched (weight batched). Further, the mixing procedure is carried out with the help of a rotary mixer. The sequence of mixing is comprised of initial mixing of fine aggregate and coarse aggregate for $1 \mathrm{~min}$. Afterwards, binder materials (Cement and Alccofine) are added and mixed well. In that dry mix, two-third of the water is added and reaming water is diluted with SP and all constituents are mixed for $5 \mathrm{~min}$ to attain uniformity. The mixing can be recommenced for extra time between the periods of testing if needed.

Totally, 132 cubes of dimensions $150 \times 150 \times 150 \mathrm{~mm}^{3}$ are prepared (12 cubes for each mix) without any form of vibration during casting. The cubes are kept undisturbed for $24 \mathrm{~h}$ at room temperature and demoulded to store in the curing tank for the respective periods. For each mix 12 cubes are tested to measure the compressive strength at 3, 7, 14 and 28 days. Samples used for the determination of compressive strength are taken out from the curing tank $1 \mathrm{hr}$ before the testing and allowed for surface drying.

\section{Methods of testing}

In this experimental work, the testing process is carried out in 2 stages. In the $1^{\text {st }}$ stage, the fresh concrete mixtures are analyzed to satisfy the requirements of SCC to EFNARC guidelines. In the $2^{\text {nd }}$ stage, the important mechanical property of compressive strength of hardened concrete at 3, 7, 14 and 28 days are examined.

\section{Analysis of fresh concrete}

The fresh properties of SCC mixtures are analyzed through Slump flow and $\mathrm{T}_{50}, \mathrm{~V}$-funnel and Lbox test to find the workability of concrete. To minimize the rate of workability loss on the test results, the mixtures are examined before the completion of $15 \mathrm{~min}$ and the fresh properties are determined. If any 
delay in testing has occurred the mixture undergoes the process of remixing for about 3 min to regain the initial homogeneity.

\section{Slump flow and $T_{50}$ tests}

The amount of deformability and ability to flow of SCC mixtures are measured by these tests. This test is similar to the traditional slump test method but the cone is placed in a flow table with a smaller diameter at the bottom and a larger diameter at the top. The size of the used flow table is $900 \times 900 \mathrm{~mm}^{2}$ and on the surface of the flow table, concentric circles of diameter from 100 to $800 \mathrm{~mm}$ are drawn to facilitate the measurement of flow easily. Before testing the flow table is levelled with the help of spirit level at the centre and corners and ensured that the table is free from moisture and impurities. Then the cone is placed at the centre of the table and the mixture is filled without any external compaction. Once the cone is filled it is lifted vertically and subsequently the time required to reach the diameter of $500 \mathrm{~mm}$ is measured. The maximum spread of the concrete is measured perpendicularly in 2 directions and the average value is recorded as slump flow. For the acceptable SCC European guidelines provided the range of values for slump flow as 550 to $850 \mathrm{~mm}$ and $\mathrm{T}_{50}$ up to $7 \mathrm{~s}$.

\section{V-funnel test}

With the help of the V-funnel apparatus, the ability to fill and the viscidity of SCC can be analyzed. The total arrangement is firmly placed on the stand without any undulation and the prepared mixture is poured into the V-funnel. Once the funnel is filled the shutter at the bottom is released and allowed the concrete to fall freely. Simultaneously the time taken by the entire concrete to flow out of the funnel is recorded using a stopwatch. The range of values suggested by EFNARC for the production of SCC is 8 $25 \mathrm{~s}$.

\section{L-box test}

The ability to pass through obstacles of the concrete mixture is determined using the L-box test for all the SCC mixtures. It is a test of the SCC's suitability for use in a member with congested reinforcement. This test is carried out with the guidelines of EFNARC and founded on the blocking ratio of concrete. The prepared mixture is filled in the vertical part of the L-box mould which is placed on the levelled surface and the concrete is opened from the gate and allowed to flow through the 3 nos of ribbed rods with $12 \mathrm{~mm}$ dimension that is placed perpendicular to the flow. The flow heights h1 and h2 are measured in the horizontal part from the gate opening to the end of the L-box. Based on the observation the blocking ratio of $\mathrm{h} 1 / \mathrm{h} 2$ is calculated and it should not be less than 0.8 as per EFNARC.

\section{Analysis of hardened concrete}

\section{Determination of compressive strength}

The compressive strength of all the series was determined with the help of a compressive testing machine of capacity 300 tons. The value is determined by taking the average from 3 nos of cubes for each mix at the age of 3, 7, 14 and 28 days. In this study, 132 cubes are cast and examined for all the mixtures to find their respective compressive values according to IS 516 (1959) [18]. If the crushing values of the cubes for a particular mix differ by $10 \%$ then results are rejected and the test has to be conducted for a $2^{\text {nd }}$ time. It is also important that the cubes should be cured properly at room temperature of $25 \pm 2{ }^{\circ} \mathrm{C}$ up to the day of testing. The cubes are taken out from the curing tank and allowed to surface drying $1 \mathrm{~h}$ before the commencement of testing.

\section{Results and discussion}

The scope of this study is to analyze the fresh and strength properties of SCC with different size of coarse aggregates and Alccofine. The investigated and discussed properties are flowability, filling ability, passing ability and compressive strength at 3, 7, 14 and 28 days. The entire mixture is designed to satisfy the EFNARC guidelines and the study intends to choose the best grade of the aggregate and optimum percentage of Alccofine that should satisfy the standards effectively.

\section{Fresh properties of SCC}

Figure 4 shows the testing fresh state of SCC in laboratory. The findings of fresh property tests such as slump flow and T50 for all the mixtures are given in Table 4. From the table, it can be observed that slump values of all the mixes are satisfied with the EFNARC guidelines except C5-A60. In this test slump values are measured between a minimum of $525 \mathrm{~mm}$ to a maximum of $690 \mathrm{~mm}$. According to 
standards, the slump values are categorized into 3 divisions such as SF1 (550 - $650 \mathrm{~mm})$, SF2 (660 - 750 $\mathrm{mm})$ and SF3 $(760-850 \mathrm{~mm})$. The applications of these categories are displayed in Table 5.

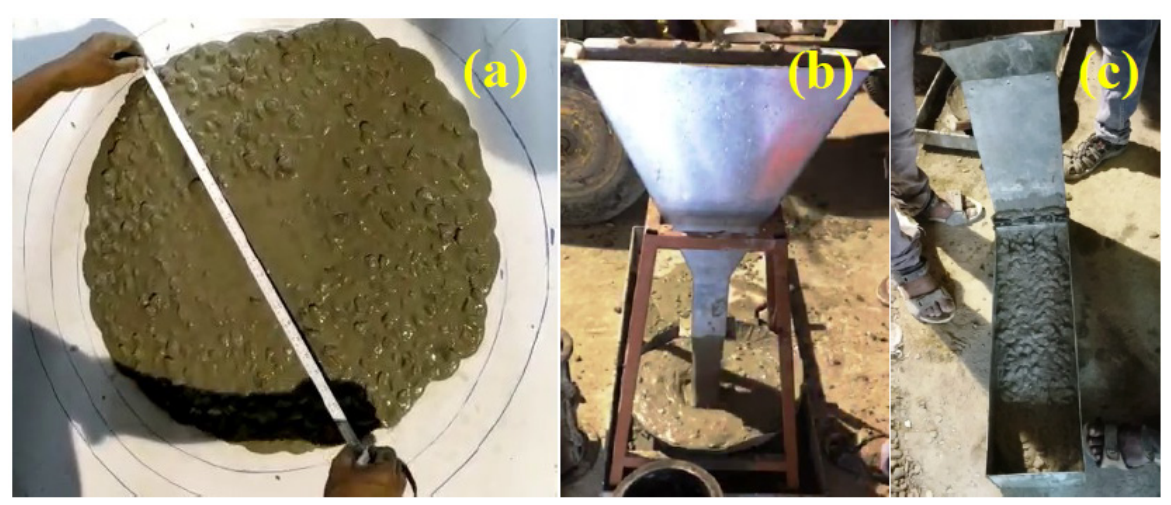

Figure 4 Testing fresh state of SCC in laboratory: (a) slump flow, (b) V-funnel and (c) L-box.

In this experimental investigation, the slump values are coming under the category of SF1 and SF2 and their ranges are illustrated as a bar chart in Figure 5. Among all the mixes of conventional SCC, the aggregate group of $10-4.75 \mathrm{~mm}(\mathrm{C} 1)$ had given better results in the slump test that is due to the lower fineness modulus of aggregate which reduced the yield stress. The presence of more fine particles in that mix enhanced the flowability. Coarse aggregates greater than $10 \mathrm{~mm}$ have non-negligible powers of inertia, which will break down surrounding clusters, allowing the shear thickening to decrease with the overall aggregate size increasing. Because of the large separation interval between the coarse aggregates, an increase in shear thickening due to grain inertia is impossible, resulting in a decrease in workability in the $\mathrm{C} 2, \mathrm{C} 3$, and $\mathrm{C} 4$ aggregate classes. Whereas in $\mathrm{C} 5(20-4.75 \mathrm{~mm})$ due to the presence of well-graded aggregates the slump flow is increased marginally. It is because of the proper distribution of aggregate sizes and packing effects that could form a single compact layer of slump flow thus improved the workability. It is observed that in all the mixes of Alccofine based SCC the flowability is gradually increased from 10 to $30 \%$ replacement of cement by Alccofine and considerably decreased from 40 to 60 $\%$. The increased flowability by Alccofine replacement up to $30 \%$ is due to the enhanced lubrication effect for the selected W/B ratio and SP dosage. The decreasing effect beyond $30 \%$ is due to the higher surface area produced by slag addition since the specific surface area of Alccofine is 5 times higher than cement. Also, the reduction in slump values is due to the rapid hydration that leads to early hardening of the matrix. Since the rate of hydration is depending upon the formation of Tri-calcium Silicate which is more than the adequate percentage of $\mathrm{C} 3 \mathrm{~S}$ in the Alccofine replacement beyond $30 \%$. These impacts may differ when the W/B ratio and SP dosage are altered since the W/B ratio and SP are kept constant in this research based on the findings of an earlier study [19].

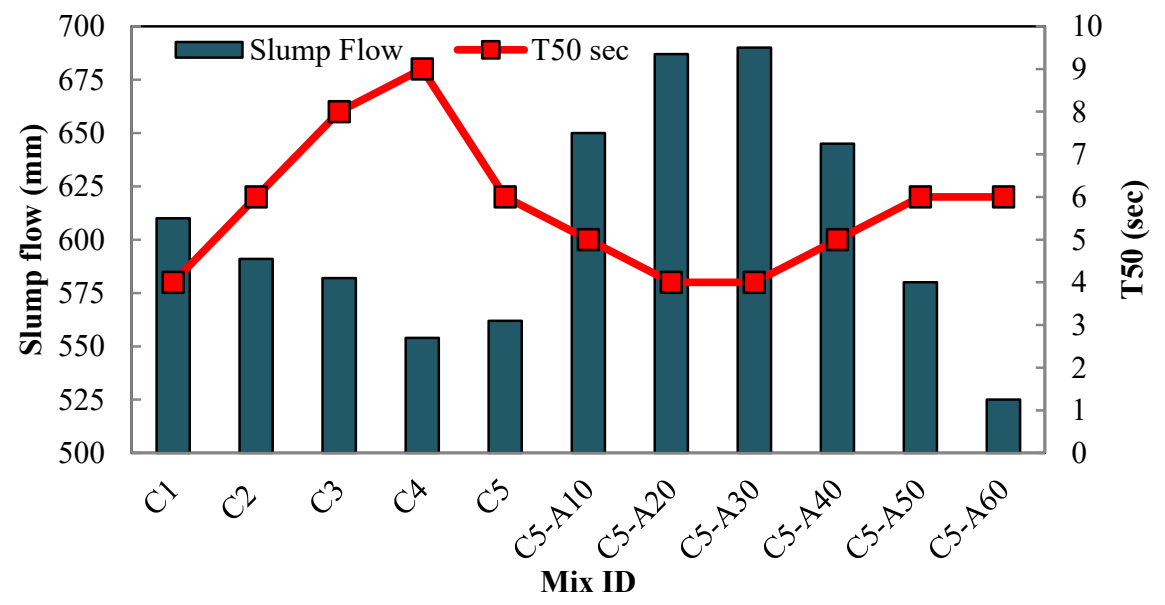

Figure 5 Slump flow and $\mathrm{T}_{50}$ time of SCC mixtures. 
Along with the slump flow, the T50 (time taken to reach $50 \mathrm{~cm}$ diameter spread) of fresh concrete is also measured and recorded. It ranges from a minimum of $4 \mathrm{~s}$ to a maximum of $9 \mathrm{~s}$ and these timings are graphically represented in Figure 5. As per standards, T50 should not exceed the time duration of $7 \mathrm{~s}$. From these test results, it is evident that the increase in aggregate size considerably increasing the T50 duration which is not preferable in SCC.

The present work is compared with some previous similar studies and their interpretation is plotted as shown in Figure 6. From the graph it is clear that increase in size of the aggregate reduced the flow properties. The single graded coarse aggregates of size 12.5 and $16 \mathrm{~mm}$ are used in many studies which helped to improve the flow properties. Single graded aggregates of size less than $12.5 \mathrm{~mm}$ such as 10,6 and $4.75 \mathrm{~mm}$ are not much preferred in practice but these are used under well graded aggregates (4.75 to $20 \mathrm{~mm}$ ). Regarding well graded aggregates, they are satisfied the flow properties as per EFNARC guidelines but not as good as single graded of size 12.5 and $16 \mathrm{~mm}$. It is to be understood that flow properties are not influenced only by aggregate size; the powder content, W/C ratio, SP dosage, chemical composition and material properties are influencing factors of flow properties.

Table 4 Fresh Properties of SCC.

\begin{tabular}{ccccc}
\hline Mix ID & Slump flow $(\mathbf{m m})$ & T50 $(\mathbf{s})$ & V-Funnel $(\mathbf{s})$ & L-Box ratio \\
\hline C1 & 610 & 4 & 4 & 0.96 \\
C2 & 591 & 6 & 6 & 0.93 \\
C3 & 582 & 8 & 11 & 0.8 \\
C4 & 554 & 9 & 14 & 0.78 \\
C5 & 562 & 6 & 6 & 0.81 \\
C5-A10 & 650 & 5 & 4 & 0.86 \\
C5-A20 & 687 & 4 & 3 & 0.95 \\
C5-A30 & 690 & 4 & 3 & 0.95 \\
C5-A40 & 645 & 5 & 7 & 0.84 \\
C5-A50 & 580 & 6 & 12 & 0.76 \\
C5-A60 & 525 & 6 & 17 & 0.7 \\
\hline
\end{tabular}

Table 5 Applications of slump flow range [6].

\begin{tabular}{cll}
\hline $\begin{array}{c}\text { Slump flow range } \\
(\mathbf{m m})\end{array}$ & Class & \multicolumn{1}{c}{ Applications } \\
\hline $550-650$ & SF1 & $\begin{array}{l}\text { 1) Unreinforced or reinforcement with minimum numbers } \\
\text { 2) Casting by a pump injection system. } \\
\text { 3) Sections those are small enough to prevent long horizontal flow. } \\
\text { Appropriate for normal applications }\end{array}$ \\
$760-750$ & SF2 & $\begin{array}{l}\text { Used for heavily reinforced structures, structures with complicated } \\
\text { shapes, or for filling under formwork. }\end{array}$ \\
\hline
\end{tabular}




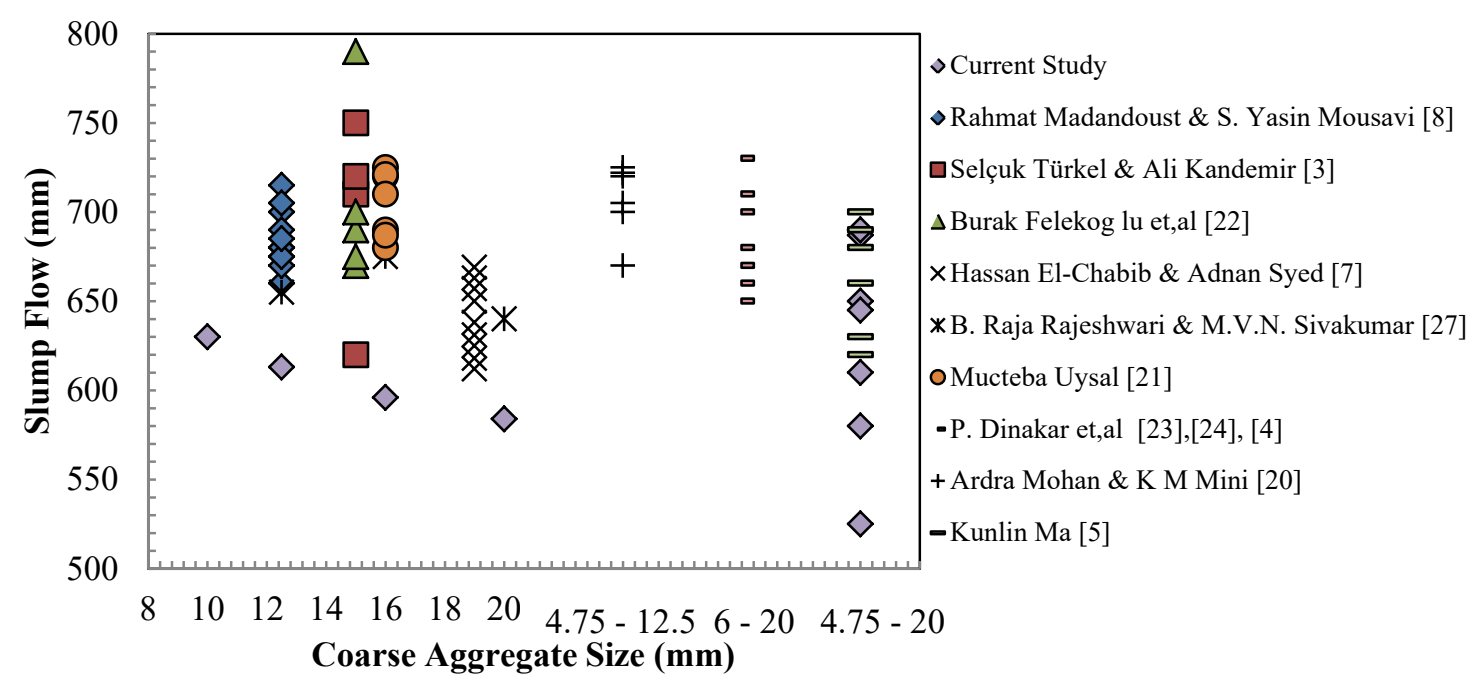

Figure 6 Size of the coarse aggregate versus slump flow of current study and previous studies $[3,5,7,8,20-24]$.

The fresh properties can be defined by yield stress and plastic viscosity since the slump flow test alone is not sufficient to define the yield stress and fresh characteristics. So, V-funnel test is carried out additionally to find the viscous behaviour of fresh concrete. The recorded V-funnel timings for all the mixtures are displayed in Table 4. Based on the values the graph is plotted for all the mixes as shown in Figure 7. From the graph, it is clear that all the mixtures are satisfying the $\mathrm{V}$-funnel timings and fall under the category of VF1 $(\leq 8 \mathrm{~s})$ and VF2 (9 - 25 s), respectively [6]. The mixes C1, C2, C5 and C5-A10 to C5-A40 are categorized to VF1 that indicates greater flowability and the remaining mixes are in VF2 (moderate flow). The aggregates of size less than $12 \mathrm{~mm}$ and the well-graded group in the conventional mix had a better filling ability. The VF time is increased due to the segregation effect since voids between the uniform-sized large aggregates (single graded) are more that cause unstable paste content in the concrete matrix when it is poured in V-funnel for testing. In essence when the paste can easily be separated from the coarse aggregates in V-funnel that tend to pass the paste content initially followed by coarse aggregates where they became inconsistent with lack of paste content resulted in increased VF time. On the other hand, mixed size of aggregates (well-graded) and smaller size aggregates are not suspected to quick segregation in V-funnel due to lesser voids between them thus reduced the VF time. In Alccofine based SCC, the viscosity of the concrete is decreased and V-funnel timings are reduced up to $30 \%$ replacement of cement by Alccofine. Further addition showed increased viscosity of concrete that was due to too much slag which could form more sticky concrete and lead to higher water demand. Where the yield stress and plastic viscosity of the fresh state concrete was decreased with an increase of slag content [25]. The viscosity of the fresh concrete is analyzed by correlating the timings of T50 and Vfunnel which is shown in Figure 8. The graph shows the relationship of $\mathrm{R}^{2}=0.994$ (Conventional SCC) and $\mathrm{R}^{2}=0.902$ (Alccofine SCC) between those timings that are in an acceptable range. Viscosity is the indicator of good flowable concrete that is analyzed by many researchers and found that higher T50 and V-funnel can reduce the acceptability of SCC [1,20-22]. 


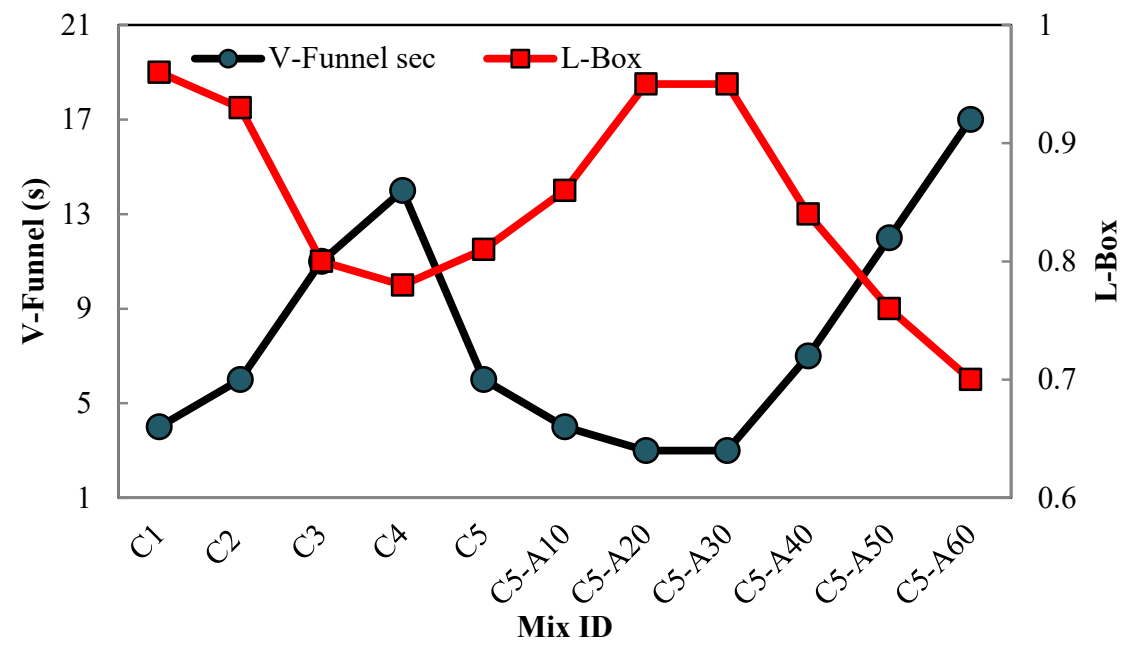

Figure $7 \mathrm{~V}$-funnel timings and L-box ratio of SCC mixtures.

The results obtained from the L-box test are listed in Table 4. The blocking ratios of the L-box test are in the range of 0.7 to 0.96 . The mixes are satisfying the EFNARC recommendations $(\geq 0.8)$ except C4, C5-A50 and C5-A60 that are out of the suggestion which is graphically shown in Figure 7. The disparity of blocking ratio in conventional SCC was due to the larger size of aggregates since smaller particles occupy gaps between larger particles and reduce the frictional forces of the matrix. In the case of Alccofine based SCC disparity was due to an excess replacement of cement by slag that leads to increased viscosity and water demand since Alccofine was 15 times smaller in size than cement and irregular in shape.

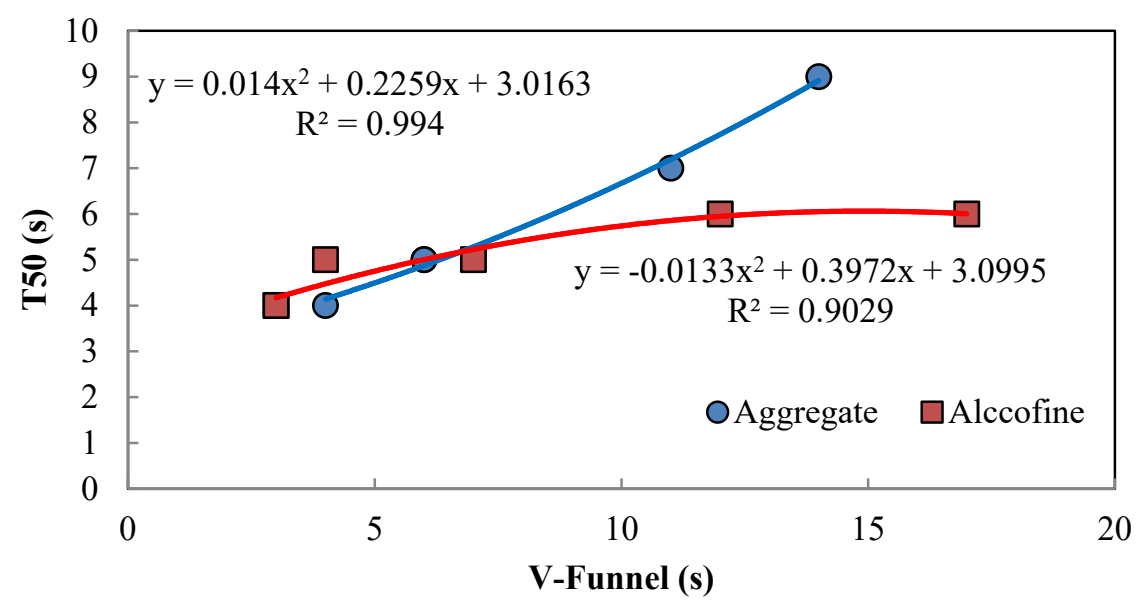

Figure 8 Correlation between $\mathrm{T}_{50}$ versus $\mathrm{V}$-funnel timings of $\mathrm{SCC}$ mixtures.

Based on the overall observation it is clear that the workability of SCC is increased with the smaller size of aggregates and vice versa whereas the well-graded aggregates showed optimum results. In that well-graded aggregate group replacement of Alccofine up to $30 \%$ showed better performance in a fresh state. In this study, it is found that the size of aggregate and percentage of Alccofine is inversely proportional to the fresh behaviour of SCC.

\section{Compressive strength}

Figure 9 shows the casting, curing and compressive testing of cubes in laboratory. The influence of the coarse aggregate size and replacement of cement by Alccofine on the compressive strength of SCC at 
the ages of 3, 7, 14 and 28 days are analyzed and their results are presented in Table $\mathbf{6}$ and graphically represented in Figure 10.
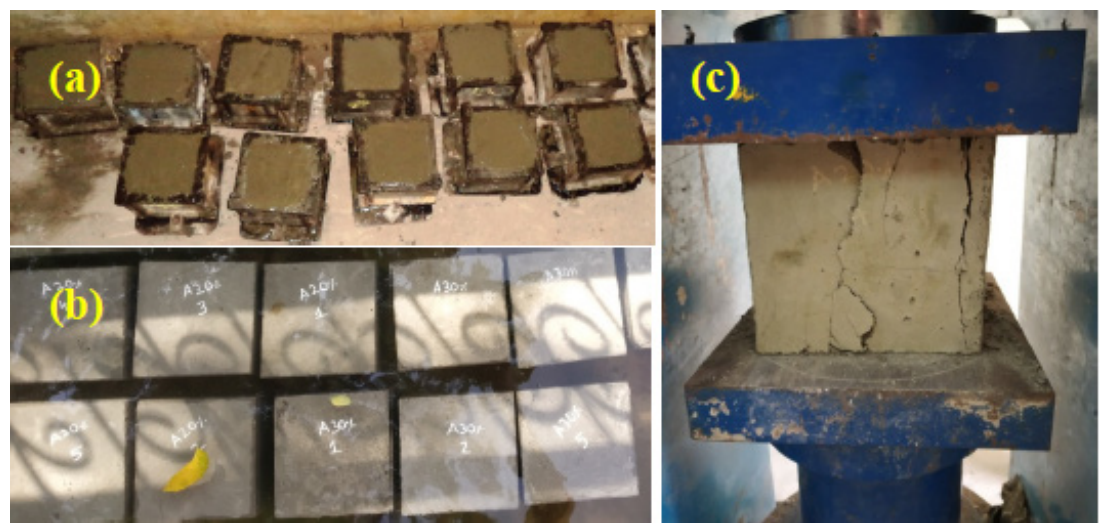

Figure 9 Testing of cubes in laboratory: (a) Casting, (b) Curing and (c) Cube failed under compression.

In conventional $\mathrm{SCC}$ mixes the aggregate groups $\mathrm{C} 1$ to $\mathrm{C} 4$ had a gradual reduction in compressive strength as their sizes get increased whereas $\mathrm{C} 5$ had good compressive strength among other mixes. The percentage of strength variations are shown in the Table 7. The strength is increased because of reduced voids in smaller sized aggregates and well-graded aggregates. Reduction in voids could enhance better packing density through all granular materials present in the concrete hence helped in strength improvement. It was evident from earlier studies that the concrete made with varying percentage of different sized aggregates ( 4.75 to $20 \mathrm{~mm}$ ) had given the better strength properties [4,23-25]. Change in size of aggregate, presence of higher mortar attached with aggregate and weak Interfacial Transition Zone (ITZ) between aggregate and paste were the reason for the reduction of compressive strength.

Table 6 Compressive strength results of SCC.

\begin{tabular}{ccccc}
\hline \multirow{2}{*}{ Mix ID } & \multicolumn{4}{c}{ Compressive strength $\mathbf{~} / \mathbf{m m}^{\mathbf{2}}$} \\
\cline { 2 - 5 } & $\mathbf{3 ~ d a y s}$ & $\mathbf{7}$ days & $\mathbf{1 4}$ days & $\mathbf{2 8}$ days \\
\hline C1 & 11.15 & 20.93 & 25.09 & 27.88 \\
C2 & 9.4 & 18.41 & 21.16 & 23.51 \\
C3 & 8.9 & 17.25 & 19.94 & 22.16 \\
C4 & 8.75 & 16.76 & 19.68 & 21.87 \\
C5 & 12.28 & 22.59 & 27.62 & 30.69 \\
C5-A10 & 13.64 & 28.12 & 30.681 & 34.09 \\
C5-A20 & 18.31 & 29.48 & 41.193 & 45.77 \\
C5-A30 & 19.25 & 32.11 & 43.317 & 48.13 \\
C5-A40 & 17.54 & 27.97 & 39.456 & 43.84 \\
C5-A50 & 14.89 & 26.81 & 33.489 & 37.21 \\
C5-A60 & 13.88 & 25.86 & 31.212 & 34.68 \\
\hline
\end{tabular}




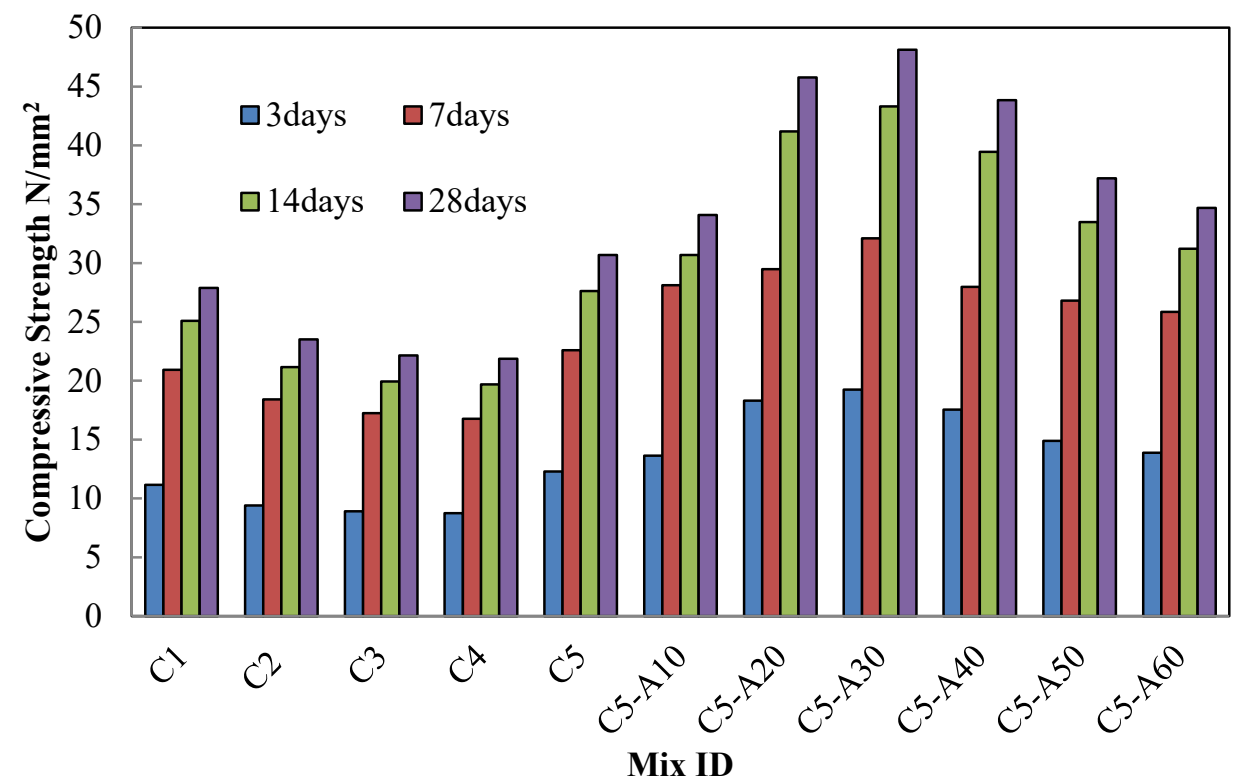

Figure 10 Compressive strength of SCC mixtures.

In Alccofine based SCC, the compressive strength is gradually increased for the mixes C5-A10 to C5-A30 and decreased further. When compared with conventional SCC, incorporation of Alccofine in SCC showed better performance since ultrafine particles of Alccofine had denser particle packing and high pozzolanic reactivity which resulted in an enhanced hydration process. Accelerated hydration on Alccofine (up to $30 \%$ ) resulted in better strength followed by the heat of hydration that leads to the dense microstructure. The increase in strength was also due to the increased total specific surface area with the presence of Alccofine. Since Alccofine is much finer than cement, it increased the water demand for a workable mix that reduced lubrication between particles thus reduced pore bonding strength (beyond 30 $\%$ ). When an excess amount of Alccofine created water demand in the matrix where part of the binder particles only got hydrated and the rest used for filling pores but not involved in hydration those remain non-reactive thus reduced the homogeneity.

Table $7 \%$ of strength variations.

\begin{tabular}{cccc}
\hline Description & $\begin{array}{c}\text { Optimum conventional } \\
\text { C5 mix compared with } \\
\text { other conventional SCC }\end{array}$ & $\begin{array}{c}\text { Optimum conventional C5 } \\
\text { mix compared with } \\
\text { Alccofine based SCC }\end{array}$ & $\begin{array}{c}\text { Optimum Alccofine C5- } \\
\text { A30 mix compared with } \\
\text { other Alccofine based SCC }\end{array}$ \\
\hline C1 & $9.6 \downarrow$ & - & - \\
C2 & $26.5 \downarrow$ & - & - \\
C3 & $32.3 \downarrow$ & - & - \\
C4 & $33.56 \downarrow$ & - & - \\
C5 & - & - & - \\
C5-A10 & - & $10.5 \uparrow$ & $34.15 \downarrow$ \\
C5-A20 & - & $39.4 \uparrow$ & $5.02 \downarrow$ \\
C5-A30 & - & $44.25 \uparrow$ & - \\
C5-A40 & - & $35.3 \uparrow$ & $9.32 \downarrow$ \\
C5-A50 & - & $19.2 \uparrow$ & $25.6 \downarrow$ \\
C5-A60 & - & $12.2 \uparrow$ & $32.5 \downarrow$ \\
\hline
\end{tabular}

Note: $\uparrow$ - Increase in percentage; $\downarrow$ - decrease in percentage. 
Figure 11 shows the SEM micrograph of C5 and C5-A30 and EDS of the same. From the picture, it is evident that $\mathrm{C} 5-\mathrm{A} 30$ had a more compact and dense matrix due to the presence of silica and alumina resulted in better refinement and a more compact binder was seen. The calcium content of Alccofine produced additional calcium-based hydration component resulted in the development of calcium silicate hydrate $(\mathrm{CSH})$ gel that is observable in the form of dense white precipitates has significantly been increased.
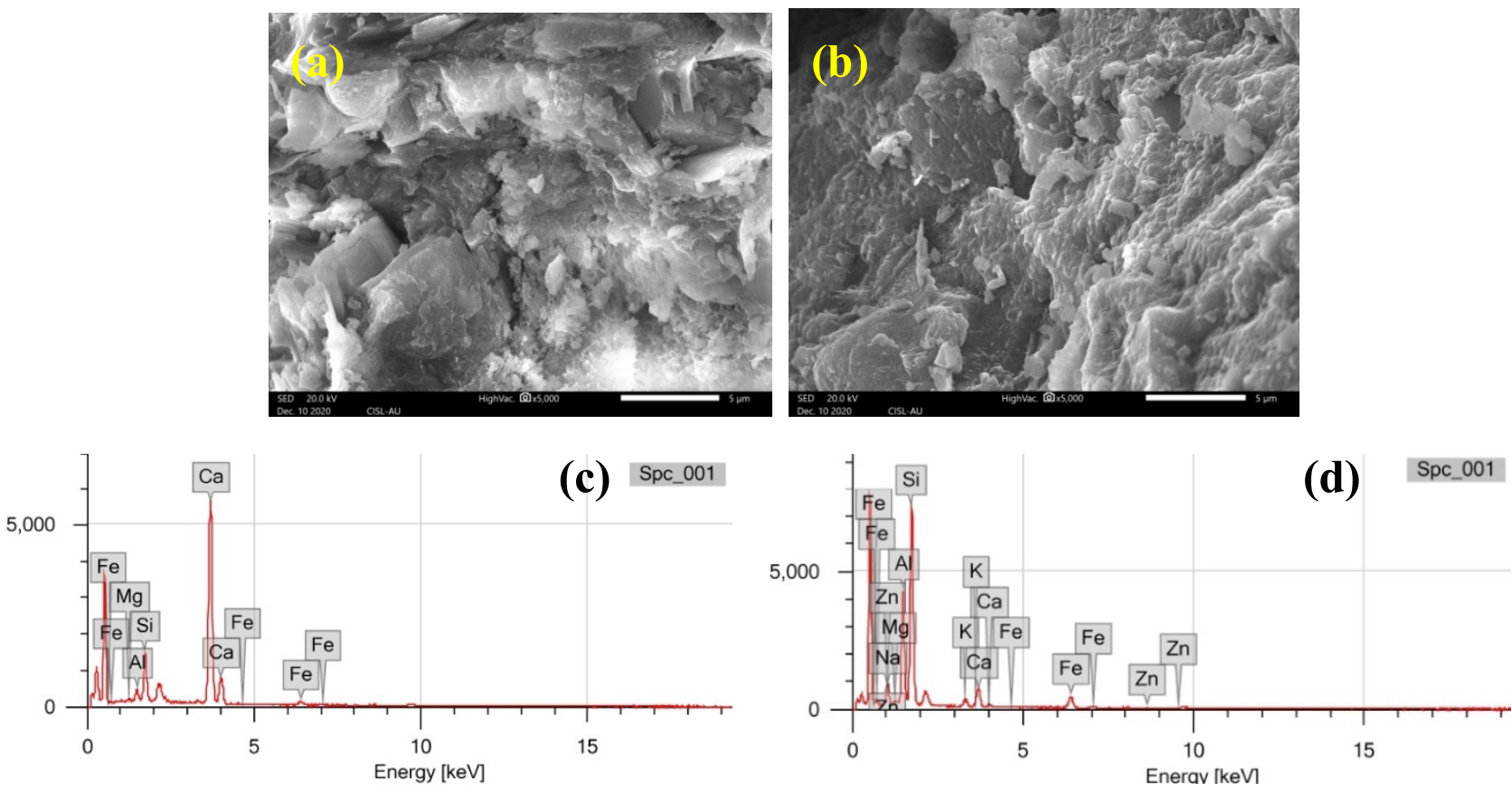

Figure 11 SEM (a) and (b) and EDS (c) and (d) outputs of mixes C5 and C5-A30.

The graph showing the varying compressive strength with respect to size of CA that are compared with some earlier studies as shown in Figure 12. From that it is comprehensible that single graded CA of size 12.5 to $16 \mathrm{~mm}$ are good in compression as fine as well graded CA also produced good results. As stated earlier the size of aggregate alone is not responsible for strength properties.

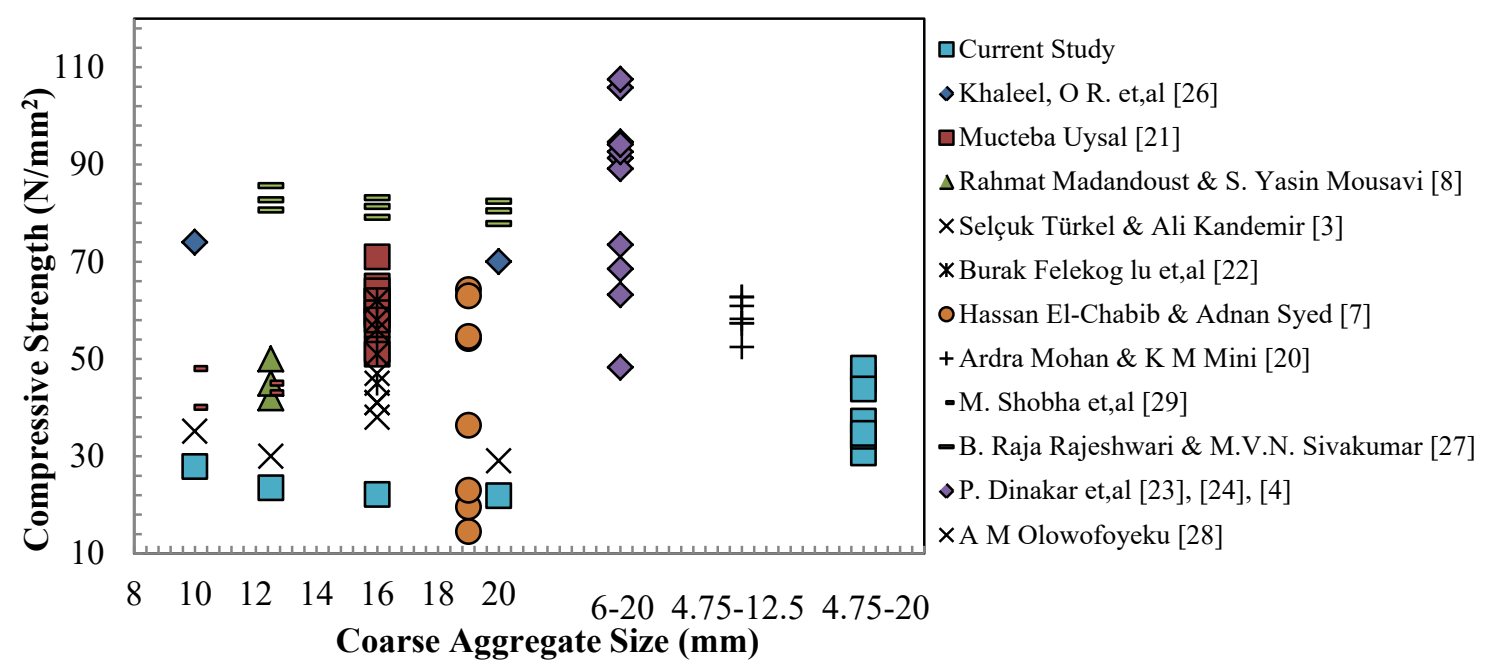

Figure 12 Size of the coarse aggregate versus compressive strength of current study and previous studies $[3,4,7,8,20,21,23,24,26-29]$. 
Similarly the graph is plotted for compressive strength with respect to varying percentage of Alccofine in normal concrete and SCC that is shown in Figure 13. From the graph it is clear that in normal concrete utilization of Alccofine is limited up to $25 \%$ and optimum results are obtained at $10-15$ $\%$ replacement. In SCC it is limited up to $15 \%$ and optimum is found to be $10 \%$ in earlier studies. In both Normal concrete (NC) and SCC researches are carried out with combined use of mineral admixtures (fly ash, GGBS, silica fume etc.,) whereas current research used only Alccofine as mineral admixture up to $60 \%$ replacement and found that $30 \%$ as optimum. This optimum replacement of Alccofine is variable depending upon the selection of materials and their mix proportion.

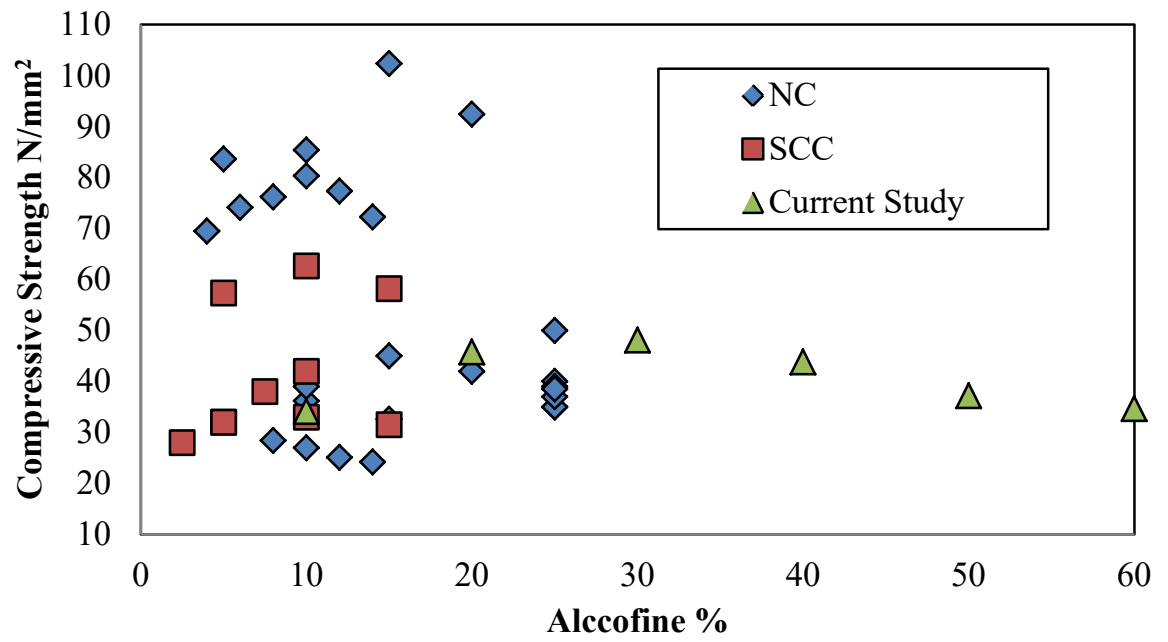

Figure 13 Alccofine percentage versus compressive strength of current study and previous studies $[10,11,20,30,36]$.

\section{Analytical investigation}

Numerical modeling and analysis were performed with FEM ANSYS software for this investigation. A Solid 65, 8 node solid elements is used to model the concrete in 3D. This element has 3 degree of freedom at every node translation in the nodal co-ordinates of $\mathrm{x}, \mathrm{y}$ and $\mathrm{z}$ directions. Solid elements capable of plastic deformation, creep, crack in tension and crushing in compression. The properties of concrete such as compressive strength, Elastic modulus and poisons ratio are the main input data based on experimental work for the design of concrete in ANSYS. The experimental and analytical values are listed in Table 8 along with their variation in results. The data reveal that error in experimental values and the ANSYS anticipated values is less than $5 \%$ there by indicating a precision level of $95 \%$. The meshing and analytical failure pattern of cube is shown in Figure $\mathbf{1 4}$ and comparison between experimental failure and modeling failure is shown in Figure 15.

Table 8 Experimental and analytical values of compressive strength $\mathrm{N} / \mathrm{mm}^{2}$.

\begin{tabular}{cccc}
\hline Mix ID & Experimental & Analytical & Difference in \% \\
\hline C1 & 27.88 & 27.3686 & -1.8342 \\
C2 & 23.51 & 23.1684 & -1.4531 \\
C3 & 22.16 & 22.3509 & 0.86128 \\
C4 & 21.87 & 21.4248 & -2.0358 \\
C5 & 30.69 & 30.802 & 0.3648 \\
C5-A10 & 34.09 & 34.0076 & -0.24159 \\
C5-A20 & 45.77 & 45.8981 & 0.27981 \\
\hline
\end{tabular}




\begin{tabular}{cccc}
\hline Mix ID & Experimental & Analytical & Difference in \% \\
\hline C5-A30 & 48.13 & 48.3094 & 0.37284 \\
C5-A40 & 43.84 & 43.9559 & 0.26431 \\
C5-A50 & 37.21 & 37.4123 & 0.54378 \\
C5-A60 & 34.68 & 34.4307 & -0.71887 \\
\hline
\end{tabular}
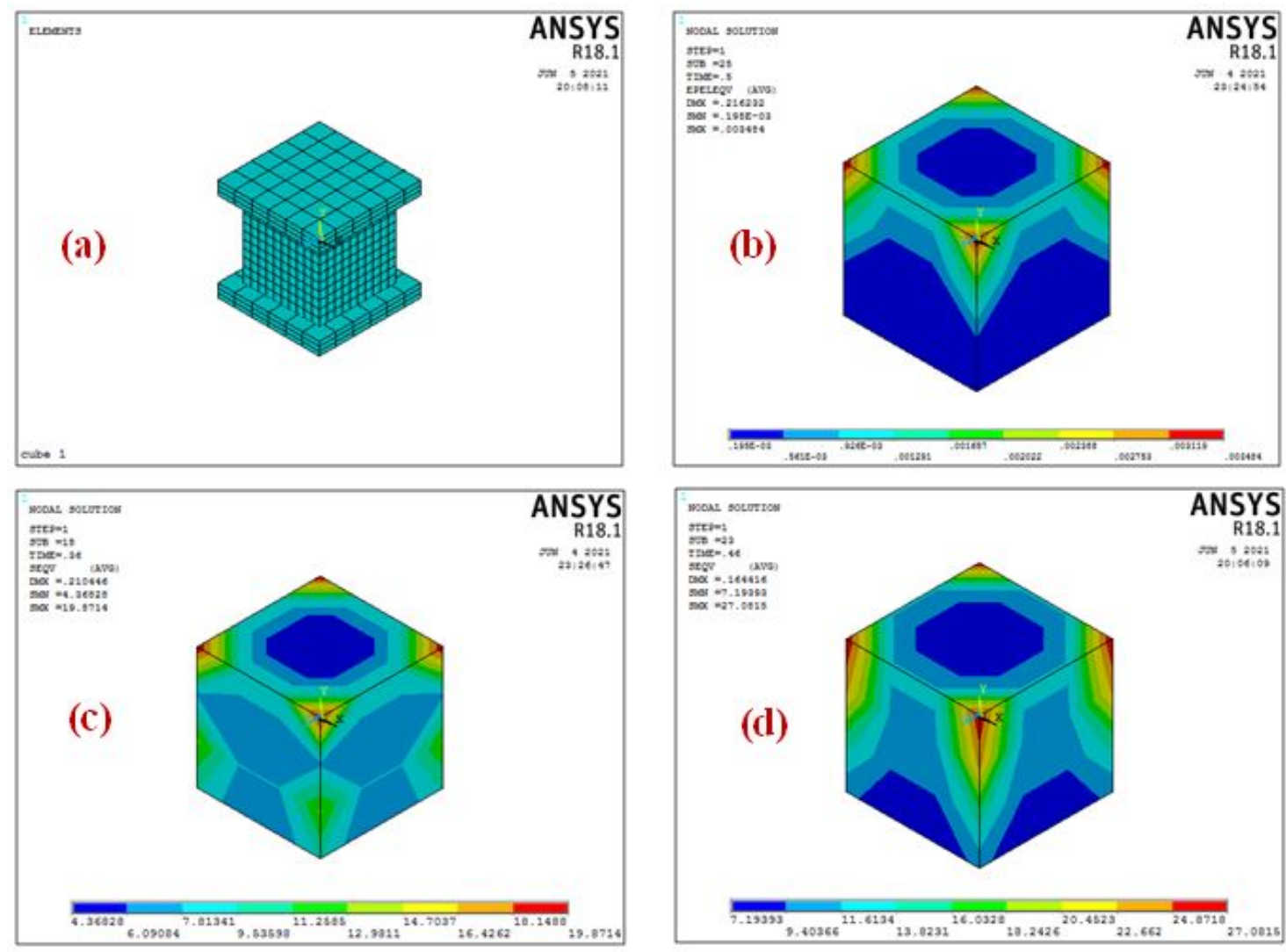

Figure 14 Analysis of cube by ANSYS: (a) meshed model, (b) occurrence of initial damage, (c) strained cube due to applied load and (d) ultimate failure.

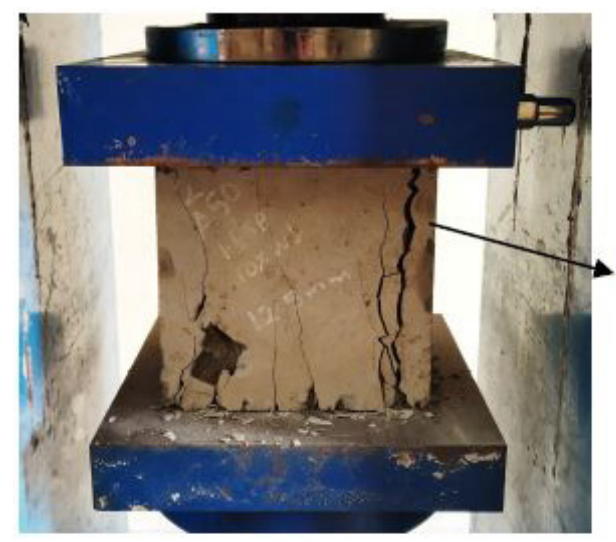

(a)

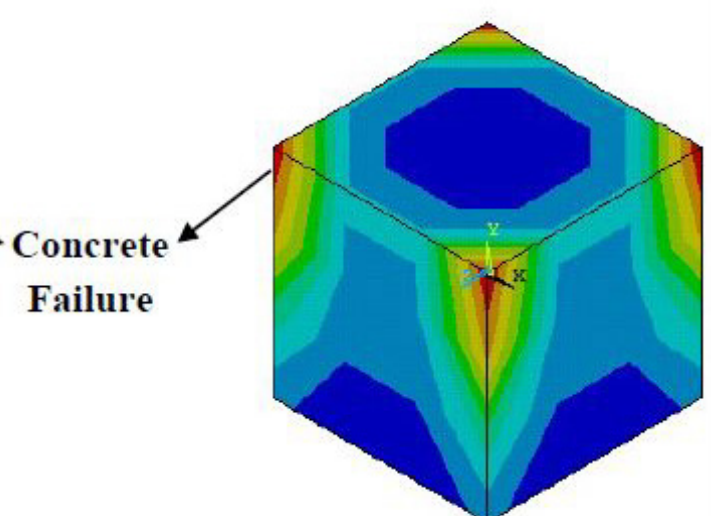

(b)

Figure 15 Comparison of failure concrete cube: (a) experimental and (b) analytical. 


\section{Conclusions}

This study was carried out to investigate the efficacy of different size of coarse aggregates on the fresh and strength properties of SCC and Alccofine based SCC.

From the findings, it is evident that the workability of SCC is increased with the smaller size of aggregates and vice versa whereas the well-graded aggregates showed optimum results due to the proper distribution of aggregate sizes and packing effects which could form a single compact layer thus improved the workability. The increased flowability by Alccofine replacement up to $30 \%$ in well-graded aggregates is due to the enhanced lubrication effect for the selected W/B ratio and SP dosage.

In conventional $\mathrm{SCC}$ mixes the aggregate groups $\mathrm{C} 1$ to $\mathrm{C} 4$ had a gradual reduction in compressive strength as their sizes get increased whereas C5 had good compressive strength among other mixes because of reduced voids. Reduction in voids could enhance better packing density through all granular materials present in the concrete hence helped in strength improvement. In Alccofine based SCC, the compressive strength is gradually increased for the mixes C5-A10 to C5-A30 and decreased further. The increase in strength was due to the increased total specific surface area, denser particle packing and high pozzolanic reactivity that resulted in an enhanced hydration process. Using well-graded aggregates and Alccofine in SCC leads to strength improvement and economic concrete production.

The consequence of FEM shows it is a reliable technique for numerical analysis that can be used to check the validity of experimental data. Further this study can be carried forward with the other mechanical properties like $\mathrm{E}$ for concrete, Modulus of rupture and flexural behaviour for better examination of this idea.

\section{References}

[1] PL Domone. Self-compacting concrete: An analysis of 11 years of case studies. Cem. Concr. Compos. 2006; 28, 197-208.

[2] GD Tsiskreli and AN Dzhavakhidze. The effect of aggregate size on strength and deformation of concrete. Hydrotech. Constr. 1970; 4, 448-53.

[3] S Turkel and A Kandemir. Fresh and hardened properties of SCC made with different aggregate and mineral admixtures. J. Mater. Civil Eng. 2010; 22, 1025-32.

[4] P Dinakar and SN Manu. Concrete mix design for high strength self-compacting concrete using metakaolin. Mater. Des. 2014; 60, 661-8.

[5] K Ma, J Feng, G Long, Y Xie and X Chen. Improved mix design method of self-compacting concrete based on coarse aggregate average diameter and slump flow. Constr. Build. Mater. 2017; 143, 566-73.

[6] European Federation of National Associations Representing for Concrete. The European guidelines for self-compacting concrete, Available at: http://www.efnarc.org/pdf/ SCCGuidelinesMay2005.pdf., accessed January 2021.

[7] H El-Chabib and A Syed. Properties of self-consolidating concrete made with high volumes of supplementary cementitious materials. J. Mater. Civil Eng. 2013; 25, 1579-86.

[8] R Madandoust and SY Mousavi. Fresh and hardened properties of self-compacting concrete containing metakaolin. Constr. Build. Mater. 2012; 35, 752-60.

[9] GGK Reddy and P Ramadoss. Influence of alccofine incorporation on the mechanical behavior of ultra-high performance concrete. Mater. Today Proc. 2020; 33, 789-97.

[10] BV Kavyateja, JG Jawahar and C Sashidhar. Effectiveness of alccofine and fly ash on mechanical properties of ternary blended self compacting concrete. Mater. Today Proc. 2020; 33, 73-9.

[11] RR Kundanati, T Malpani and V Sairam. Study on mechanical properties of mortar using alccofine and graphene oxide. In: Proceedings of the $2^{\text {nd }}$ International Conference on Martials, Manufacturing and Modelling, Tamil Nadu, India. 2020, p. 2431-8.

[12] P Haldar and S Karmakar. An experimental study on the fatigue properties of Alccofine-based crumb rubber concrete. Proc. Inst. Civil Eng. Eng. Sustain. 2021; 174, 235-50.

[13] SC Boobalan, VA Srivatsav, AMT Nisath, AP Babu and V Gayathri. A comprehensive review on strength properties for making Alccofine based high performance concrete. In: Proceedings of the $2^{\text {nd }}$ International Conference on Aspects of Materials Science and Engineering, Chandigarh, India. 2021, p. 4810-2.

[14] B Sagar and S MVN. Mechanical and microstructure characterization of Alccofine based high strength concrete. Silicon 2021, DOI: 10.1007/s12633-020-00863-X.

[15] Bureau of Indian Standards. Specification for 53 grade ordinary Portland cement. Dee Kay Printers, New Delhi, India, 1988. 
[16] Bureau of Indian Standards. Specification for coarse and fine aggregates from natural sources for concrete. Bureau of Indian Standards, New Delhi, India, 1970.

[17] Bureau of Indian Standards. Concrete admixtures - specification. New India Printing Press, Khurja, India, 1999.

[18] Bureau of Indian Standards. Methods of tests for strength of concrete. Simco Printing Press, Dehli, India, 2004.

[19] C Prithiviraj and J Saravanan. Influence of W/B ratio and chemical admixture on fresh and hardened properties of self compacting concrete using Alccofine. J. Xidian Univ. 2020; 14, 490615 .

[20] A Mohan and KM Mini. Strength studies of SCC incorporating silica fume and ultra fine GGBS. Mater. Today Proc. 2018; 5, 23752-8.

[21] M Uysal. The influence of coarse aggregate type on mechanical properties of fly ash additive selfcompacting concrete. Constr. Build. Mater. 2012; 37, 533-40.

[22] B Felekoglu, S Turkel and B Baradan. Effect of water/cement ratio on the fresh and hardened properties of self-compacting concrete. Build. Environ. 2007; 42, 1795-802.

[23] P Dinakar. Design of self-compacting concrete with fly ash. Mag. Concr. Res. 2012; 64, 401-10.

[24] P Dinakar, KP Sethy and UC Sahoo. Design of self-compacting concrete with ground granulated blast furnace slag. Mater. Des. 2013; 43, 161-9.

[25] O Boukendakdji, EH Kadri and S Kenai. Effects of granulated blast furnace slag and superplasticizer type on the fresh properties and compressive strength of self-compacting concrete. Cem. Concr. Compos. 2012; 34, 583-90.

[26] OR Khaleel, SA Al-Mishhadani and HA Razak. The effect of coarse aggregate on fresh and hardened properties of self-compacting concrete (SCC). Proc. Eng. 2011; 14, 805-13.

[27] BR Rajeshwari and MVN Sivakumar. Influence of coarse aggregate properties on specific fracture energy of steel fiber reinforced self compacting concrete. Adv. Concr. Constr. 2020; 9, 173-81.

[28] AM Olowofoyeku, OM Ofuyatan, J Oluwafem and O David. Effect of various types and sizes of aggregate on self-compacting concrete. In: Proceedings of the $1^{\text {st }}$ International Conference on Sustainable Infrastructural Development, Ota, Nigeria. 2019, p. 012054.

[29] DH Mohan, M Shobha and PSN Raju. Aggregate size and behaviour of self-compacting concrete. 2006; 159, 147-52.

[30] RS Khatana, P Aggarwal and Y Aggarwal. Effect of Alccofine on fresh and hardened properties of self compacting concrete $I n$ : Proceedings of the National Conference on Technological Innovations for Sustainable Infrastructure, Calicut, India. 2015, p. 34-8.

[31] D Sharma, S Sharma and A Goyal. Utilization of waste foundry slag and Alccofine for developing high strength concrete. Int. J. Electrochem. Sci. 2016; 11, 3190-205.

[32] A Narender Reddy and T Meena. A study on compressive behavior of ternary blended concrete incorporating Alccofine. In: Proceedings of the International Conference on Materials Manufacturing and Modelling, Vellore, India. 2018, p. 11356-63.

[33] B Muralikrishnan and J Saravanan. Effect of Alccofine and ggbs addition on the durability of concrete. Civil Eng. J. 2019; 5, 1273-88.

[34] PN Reddy and JA Naqash. Properties of concrete modified with ultra-fine slag. Karbala Int. J. Mod. Sci. 2019; 5, 151-7.

[35] B Sagar and MVN Sivakumar. An experimental and analytical study on Alccofine based high strength concrete. Int. J. Eng. 2020; 33, 530-8.

[36] PN Reddy, BB Jindal, BV Kavyateja and AN Reddy. Strength enhancement of concrete incorporating Alccofine and snf based admixture. Adv. Concr. Constr. 2020; 9, 345-54. 